\author{
Journal of Philosophy of Emotion \\ Volume 3, No. 2, 2022 (Winter)
}

\title{
Author's Replies \\ Replies to Contesi, Hardcastle, Pismenny, and Gallegos
}

\author{
Andreas Elpidorou \\ University of Louisville, Kentucky, USA
}

Elpidorou, Andreas. 2022. "Replies to Contesi, Hardcastle, Pismenny, and Gallegos.” Journal of Philosophy of Emotion 3, no. 2: 44-77. https://doi.org/10.33497/2022.winter.6.

\begin{abstract}
The commentaries by Contesi, Hardcastle, Pismenny, and Gallegos pose pressing questions about the nature of boredom, frustration, and anticipation. Although their questions concern specific claims that I make in Propelled, they are of broad philosophical interest for, ultimately, they pave the way for a better understanding of these three psychological states. In my responses to the commentators, I clarify certain claims made in Propelled; provide additional support for my understanding of frustration; articulate the relationship between effort and value; defend the claim that boredom is an emotion and discuss its formal object; and finally, consider the relationship between boredom (ordinarily understood) and deep or profound boredom. I am grateful to the commentators for engaging with Propelled.
\end{abstract}

Keywords: boredom; frustration; anticipation; effort; aesthetic emotions; ambivalence; mood; formal object; the good life

\section{REPLY TO CONTESI: FOUR NOTES ABOUT PROPELLED}

Filippo Contesi raises a number of critical points. First, he contends that if one of the book's aim is "to create a rapprochement between existentialism and analytic philosophy, then that aim is less than optimally achieved." Second, he brings under scrutiny the sense in which negative emotions are "necessary" for the good life according to Propelled. Third, he states that there are relevant philosophical works that I did not acknowledge in Propelled. He also comments on two experimental studies discussed in the book and argues that they do not

Andreas Elpidorou @ 2022. Author email: andreas.elpidorou@louisville.edu 
necessarily support my position. Finally, he discusses the "paradox of negative emotions" and argues that my discussion of art in Propelled denies an "apparent contrast between art and real life."

\section{On the Ideas of An Existentialist Cognitive Science Or of An Existentialist Analytic Philosophy}

Does Propelled argue for the possibility of an existentialist cognitive science? Does it argue for a type of analytic philosophy grounded in existentialism? The answer to both questions is the same: "No." The book advances no meta-philosophical claims, nor does it aim to convince readers of the compatibility of different theoretical approaches. Consequently, whether the project succeeds in creating "a rapprochement between existentialism and [the type of empirically informed] analytic philosophy" that I engage in, is not, I suggest, a relevant criterion by which to judge its success or failure. All the same, the book does engage with existentialism and for that reason, I am compelled to say a word or two about the role that existentialism occupies in Propelled.

I find much value both in existentialism and (existential) phenomenology. First, existentialism's emphasis on human freedom is integral to the concept of the good life that Propelled develops. The good life, I admit, can be many things, but it has to be a life that appears to be one's own (for further discussion, read the précis). Existentialism's focus on freedom and transcendence (projection) exemplifies the conception of the (or a) good life that I defend in Propelled. For that reason, existentialist sources (especially de Beauvoir 2014) inform my claims about human action and rationality (see Elpidorou 2020, 128-31, 152-59). Furthermore, I am influenced by a broadly phenomenological understanding of emotions. Such an understanding conceives of emotions as integral parts of human existence, takes seriously their experiential character, and articulates the ways in which having emotions ought to be understood as an ongoing social and embodied project. And so, existentialism informs the general outlook of the book when it comes to the claim that human life is motion[1] (and projection), whereas phenomenology informs my understanding of emotions as ways of existence (Elpidorou 2020, 12-19). Yet these two important sources of philosophical influence do not amount to the further claim that Propelled aims to bring together different traditions. I am not convinced that such a rapprochement is necessarily possible (read Elpidorou 2018c for a discussion of the limitations of naturalizing phenomenological-existentialist approaches on emotions). Nor is it my aim to propose a reconciliation between two importantly different traditions. The aim of the book is a humbler one. It argues for the importance of negative emotions and states of discontent in the good life.

\section{Two Senses Of "Necessary"}

Contesi is certainly right to point out that I often talk about the "necessary" role that negative emotions and states of discontent play in the good life. Indeed, this is one of the main claims of Propelled. He is also right to claim that "necessary" can mean different things. So, in what sense are such states necessary? There are two senses of "necessary" that are involved in the book: a weak and a strong sense.

The weak one amounts to the claim that negative emotions and states of discontent are useful tools for the pursuit of the good life, assuming that the subjects of such lives are neurotypical agents affected and motivated by their drives and affective states. An imperfect but useful analogy with pain helps to illustrate this meaning of "necessary" (see also Elpidorou 2018b). Pain is a negative sensation that most of us wish to avoid. Yet we wouldn't want to live without the capacity to experience pain. We know that subjects with congenital insensitivity to pain live difficult and often short lives. Without the experience of pain to warn them of bodily harm, they are often incapable of protecting themselves from such harm. I am, of course, oversimplifying 
matters here-for one, I pass over ways in which one can protect one's body from noxious stimuli in the absence of the sensation of pain - but the point that I wish to make should be clear: for most of us, the capacity to experience pain is, in a sense, necessary. Not necessary insofar as it is impossible to exist without it. But necessary insofar as it serves a beneficial role: the experience of pain helps us to avoid bodily harm and to take care of our bodies when they have been harmed. Propelled argues for a similar claim when it comes to boredom, frustration, and anticipation: although unpleasant, such psychological states can be beneficial to us. They are our guides and tools for the pursuit of the good life (read the précis, for more on this claim).

But there's another meaning of "necessary" that Propelled utilizes. The book argues that a life without boredom, frustration, and anticipation won't be recognizably human. I argue at length for the necessity of anticipation in the construction of the self and of a personal life in Propelled (Chapters 8, 9, and 150-160). I also discuss, although somewhat briefly (111-12), the intimate connection between frustration and desire and suggest that without the experience of frustration our notion of desire would be completely transformed (or even disfigured) (read Kupperman 2006 for an illuminating discussion on this point). Indeed, what does it mean to desire something if we are never frustrated by its absence? What kind of motivation would we have to satisfy desires and overcome obstacles if we were never frustrated (read Chapter 6)? Lastly, boredom might also be necessary in the sense that a life without boredom would be a life in which everything strikes us as interesting or worth engaging with. Again, this appears to be a life that is dissimilar, in important respects, from our own. What makes a life personal is the fact that we have preferences and interests, and that we commit to and invest in certain projects but ignore and reject others. A life emptied of boredom would signify the lack of a demarcation between what we find interesting and uninteresting, between what strikes us as meaningful and meaningless, and between what we think is worth pursuing and that which we think is not. Thus, boredom, frustration, and anticipation are necessary not just in the weak sense that they are often useful tools in the pursuit of the good life, but also in the sense that they appear to be the conditions necessary for the experience of a personal life.

\section{More Philosophy, More Science}

Contesi also claims that Propelled could have engaged more with pertinent philosophical sources and that it should have been more critical of some of the empirical studies on which it relies. It's hard to disagree with the spirit of Contesi's two-fold claim. Most philosophical works would benefit from more engagement with the existing philosophical literature, although one should be mindful of the costs that such an additional engagement might carry. And a critical engagement with the empirical studies, as long as it is fair to the work of the scientists, isn't merely welcome but obligatory for works that aim to draw philosophical conclusions from such studies.

Philosophical Engagement. Consider first the issue of whether there are some philosophical positions that needed to be discussed in Propelled. In his commentary, Contesi notes the following:

Schopenhauer's views might have for instance enriched Elpidorou's discussion of the empirical research on emotional adaptation . . . [and] Elpidorou's discussion of psychological studies on self-administration of electric shocks to escape states of boredom . . . would have been nicely complemented, if only again for the sake of acknowledging past contributions, by a discussion of Edmund Burke's view that we sometimes seek moderately negative emotions to escape the dullness of boredom. 
It is true that I don't discuss Schopenhauer's view in my presentation of boredom but that was intentional and strategic. It is hard to dissociate Schopenhauer's view of human psychology from his contentious and somewhat abstruse metaphysical views regarding the world and the will. A discussion of the former would have required me to discuss the latter and I found such a discussion not only unnecessary but counterproductive to the aims of the book. Furthermore, the Schopenhauerian view that Contesi has in mind appears in my discussion of Beckett's Proust. In that work, Beckett repeats the Schopenhauerian contention that life is a pendulum that swings from the pain that we experience when our desires are unfulfilled to the tedium that we feel when our desires are met. What about Burke? Contesi doesn't give page references to Burke's work, so I cannot discuss the specific passages that he has in mind. As far as I can tell, however, Burke doesn't discuss the motivating power of boredom and has very little to say about how negative emotions can motivate us to seek out maladaptive and harmful behaviors. Lastly, although it is true that Propelled doesn't discuss every philosopher who has said something of value regarding the psychological states that are of central interest, it does discuss a large number of thinkers (philosophers and non-philosophers alike) who have offered important insights. The list is long, so I won't name names here, but the interested reader can look at the references.

Alice in Wonderland and the IKEA Effect. Contesi's most critical points concern my use of the two experimental studies (van Aart et al. 2010; Norton et al. 2012) that he discusses in his commentary. The paper by van Aart and colleagues (2010) is used in Propelled as an illustration of the motivating potential of boredom. It is suggestive but by no means conclusive. The experiment itself is noteworthy. The researchers built an installation involving both virtual and augmented reality elements in an attempt to recreate a narrative arc from Lewis Carroll's Alice's Adventures in Wonderland. The researchers asked participants to complete a tedious task (folding sheets of paper) and then observed their behavior as they were approached by a mechanical, pink-eyed, jacket-and-scarf-wearing, and watch-carrying rabbit. The aim of the researchers was to determine whether the participants would follow the rabbit and explore the environment. If a participant didn't follow the rabbit, the rabbit would make another "run," trying to entice the participant into following it and exploring the environment. If necessary, the rabbit would make a maximum of three appearances and during its last appearance it would invite the participants to follow it. Through a hidden walkie-talkie, the mechanical rabbit could talk.

Contesi objects that the role of boredom in motivating subjects' behavior is overstated in Propelled. He contends that the design of the experiment was to test for the "motivational role of the combination of boredom and curiosity." Contesi also adds that given the structure of the experiment (specifically, the way that the installation was built and the presence of the mechanical rabbit), it is to be expected that participants would become curious by their surroundings and such a rise ought to be considered the primary driving force behind their behavior. He notes further that compliance is an important factor when considering the subjects' behavior. During its final run, the rabbit explicitly asked participants to follow it. Thus, the subjects might have decided to explore the environment not because of their boredom or curiosity, but because they were following instructions.

To be clear, in my discussion of this experiment in Propelled, I explicitly mention the possible role of curiosity in affecting the subjects' behavior (Elipodorou 2020, 58-9). Still, an emphasis on boredom when reporting the study appears warranted. First, all indications show that the subjects experienced boredom while performing the tedious task. So, the manipulation was successful. Second, my presentation is in line with what the researchers themselves concluded: namely, that boredom played an important role in driving behavior. In fact, according to 
the reported findings, the boring task made the participants more curious. Thus, even if curiosity is taken to be the proximal cause of exploration (assuming, of course, that we can somehow disentangle the respective effects of each emotional state), boredom still remains an important influence on the subjects' behavior, even if it is a slightly more remote cause of behavior (read van Aart et al. 2010, 134). Lastly, compliance is insufficient to account for the observed findings. As it is reported by van Aart and colleagues, and mentioned in Propelled, all but one of the subjects explored the environment before they were explicitly instructed by the mechanical rabbit.

Whatever one makes of this experiment, I should be quick to underline that I do not use it as the sole support for the claim that boredom is an affective experience capable of motivating individuals to pursue alternative goals and tasks. The main use of the van Aart and colleague's study is to tell a story and to engage the reader. Strong empirical evidence for the claim that boredom can act as a motivating factor abounds in the literature, and in Propelled I cite numerous studies that demonstrate that the experience of boredom is related both to the presence of a strong motivation to alleviate feelings of boredom (Fahlman et al. 2013; Van Tilburg and Igou 2012) and to an array of behavioral outcomes indicative of one's efforts (often extreme) to escape boredom (e.g., Bench and Lench 2019; Bench, Bera, and Cox 2020; Havermans et al. 2015; Nederkoorn et al. 2016; Pfattheicher et al. 2020; Wilson et al. 2014)

The second study that Contesi considers is a famous one. It is the study that gave rise to the idea of the "IKEA effect" (Norton et al. 2012). The term "IKEA effect" refers to the observation that consumers tend to place a higher value on products they themselves constructed compared to identical items that they did not construct. I do take this study more seriously than that of van Aart and colleagues and I do think that it offers some (although not conclusive support) for an important contention that I advance and defend in Propelled, namely, that investing effort in an activity changes the manner in which we appraise it. Specifically, an activity that is judged by us to be more effortful tends to be appraised as being more valuable.

In his discussion of the study, Contesi writes the following:

[T] he specific contribution of the Norton et al. study, is by their own design, to control for the role of successful (vs. unsuccessful) completion of the subjects' effortful aim. Indeed, taking into account their follow-up experiments, reported in the same article, Norton et al. suggest that the crucial factor for the emergence of "the Ikea effect" is not merely effort but successful (and lasting) completion of labour. This is backed up by their discovering that no increase in perceived monetary value follows from either unsuccessful completion of subjects' building efforts, or the destruction of their artefact (by their own hands).

Contesi concludes that what the experiment shows is an effect of successful completion on one's willingness to pay more for a product and not an effect of the investment of effort. Thus, "Norton et al.'s study is, in the relevant context, not the most relevant source of evidence for Elpidorou's point."

Much can be said both in response to Contesi's point and about the study. I restrict my discussion to the following three points: 
1. The experiment that considers the effect of completion on subjects' willingness to pay is Experiment 2 (Norton et al. 2012) and not the IKEA study (Experiment 1) that I discuss in Propelled. In this experiment, the subjects weren't given an IKEA box but a set of LEGO bricks. Researchers divided participants into pairs, and each participant was randomly given one of four sets of LEGO bricks and assigned to one of three conditions (build: participants built the set themselves; pre-assembled: the given LEGO set was already assembled; and unbuild: participants built the set but then took it apart). The researchers then asked participants to place bids on both their own sets and on their partner's set. The results show that participants valued their LEGO sets more than their partner's when they built them themselves. The researchers write: "Only in the build condition, as predicted, were participants' bids for their own creation significantly higher than their bids for their partners' creations ... Building and then 'unbuilding' sets, however, caused this difference to become non-significant" (Norton et al. 2012, 458). Although this is an important result, it would be unduly quick to conclude that completion is the driving factor here. Asking someone to "unbuild" a set that they have built affects the manner in which they appraise it. In fact, a demand to destroy the set is very likely to give rise to the belief or judgment that the effort exerted while building the set has been a waste of time. Consequently, the reported difference between the build and the unbuild condition might not lie in the fact that in only one of the conditions (build) individuals were able to complete the assembly of the set. Instead, the difference could lie in the fact that although effort positively affected the perceived value of the set (in both conditions), its effect was counteracted only in the unbuild condition by a demand to destroy the fruits of one's effort and labor. Such an alternative explanation accounts for both the reported differences between the two conditions (build vs. unbuild) and also permits effort to play a positive role in the valuation of the product.

2. In a follow-up study, the same group of researchers revisited the question of why products that we build are perceived by us to be more valuable than pre-built ones. They found that feelings of competence (as measured by feelings of pride) that arise from successful self-creation (assembling a LEGO car) were significantly related to subjects' willingness to pay for a product (a measure of value) (Mochon et al. 2012). Importantly, the researchers also showed that although putting together the LEGO set was a significant predictor of willingness to pay for the set (i.e., individuals were willing to pay more for sets that they assembled compared to pre-assembled ones), this effect became non-significant when competence (as measured by feelings of pride) was included in a regression model. In other words, what might explain the subjects' willingness to pay more for LEGO sets that they themselves assembled is the presence of a feeling of pride that is associated with the successful assembly of the LEGO set and not necessarily the fact that they completed the assembly.

3. To complicate matters even further, a more recent study by Sarstedt and colleagues (2017) replicated the original IKEA effect, however, they found no support for the mediating role of pride (contra to Mochon et al. 2012). What they found instead was support for the mediating role of psychological ownership. It is unclear how to interpret the null finding concerning pride-Sarstedt and colleagues used a different conceptualization of pride than Mochon et al 2012. Still, it is important to keep in mind that the presence of effort might affect both pride and psychological ownership: there appears to be a conceptual relationship between pride and effort (we take pride in activities that we have invested effort in them) and experimental evidence in support of the claim that effort and ownership are related 
(Kanngiesser and Hood 2014). Lastly, it is worth noting that when Sarstedt and colleagues compared the effects of incompletion on subjects' willingness-to-pay, they did notice a reduction in subjects' willingness-to-pay (compared to the completion condition), yet that result was not significant, something that compels us to be critical of Norton et al. (2012)'s interpretation of their Experiment 2.

All this is to say, the IKEA effect is the topic of on-going empirical work. But does that mean that effort can explain the IKEA effect? Not necessarily. The role of effort in the IKEA effect is proposed as an empirical hypothesis that should be either confirmed or disconfirmed. Although the presence of effort affords one explanation of the IKEA effect, it isn't the only one. Indeed, the underlying mechanisms of the IKEA effect are not yet completely known (for a useful discussion, read Marsh et al. 2018). All the same, as I point out in Propelled, the IKEA effect is just one empirical phenomenon that can be brought in support of the important role that both effort and labor play in how we understand and appraise value. There is a wealth of both empirical and theoretical considerations that strongly support an interaction between effort and value. For reviews and discussions, read Burgmer, Forstmann, and Stavrova (2019) and Inzlicht, Shenhav, and Olivola (2018). We might not yet have the definitive account of the psychological mechanisms behind the IKEA effect. Nonetheless, given our current knowledge and available studies, the claim that effort and value are related stands on firm ground.

\section{The Psychology of Art and The Psychology of Life}

I was surprised to read that Propelled advances a thesis about the nature of our psychological responses to art and how they compare to our responses to real-life situations. Contesi writes: "Although Elpidorou does not cite the aesthetic literature on the topic, his thrust in the book may be understood in part as denying this apparent contrast between art and real life." Despite this attribution, Contesi does not provide textual evidence in support of his reading of my book. What passages commit me to this reading? And what claims are suggestive of a denial of the "apparent contrast between art and real life"? My questions are rhetorical. I am not asking for textual evidence. I am merely registering my surprise. Indeed, it would be exceedingly hard to find textual evidence for a claim that I neither articulate nor defend in the book.

Even though I make no claims about the relationship between art and real life, I do discuss examples of art in Propelled. I talk about musical composition and performance (Erik Satie's Vexations), film (Andy Warhol's Empire), video games (QWOP or Getting Over It with Bennett Foddy), and fiction (Herman Melville's Bartleby, the Scrivener, Yuri Olesha's Envy, Milan Kundera's The Joke, and others). The examples, however, are never used to deny in any way the existence of a difference between life and art, nor to suggest that our psychological responses to real-life situations are similar to those of art. Take the case of Bartleby, the Scrivener. When reading the text, we don't mistake ourselves for Bartleby. We do not think that we have to endure the tedium of copying legal documents. And, more generally, we do not take our world to have changed in response to what we read in the text. Bartleby's death is still his; the lawyer's apprehension, anxiety, and frustration are not ours. Or consider Getting Over It with Bennett Foddy. When we play the game, we might become frustrated with the lack of our progress. But we don't lose ourselves in the game. We don't confuse our frustration with that of the avatar's-the half-naked man stuck in a caldron that we control. Nor are we incapable of understanding that we are frustrated with our progress in the game and not with the obstacles (boulders, beach balls, heaps of garbage, etc.) that the avatar cannot overcome. 
The distinction between real life and art is undeniable. The cases that I offer in Propelled do not mean to suggest, in the slightest, that the distinction isn't there. So, what is the role of those discussions in Propelled? They serve primarily as textual lenses: they are ways of focusing the reader's attention on certain features of the psychological states in question. Thinking about Bartleby, I argue, allows us to acknowledge the value and centrality of anticipation in the construction of a human life. Reflections on the difficulty of playing Getting Over It with Bennet Foddy show how the experience of frustration can be motivating and even an attractive feature of a video game. Lastly, the examples of artworks that involve boredom are meant to illustrate that boring art--because of its volitional, experiential, and cognitive features--is a risky but potentially profound artistic gesture. It is risky because boring artworks are intentionally designed to be experienced as having no aesthetic properties whatsoever. What is significant about boredom (and quite different from the other negative emotions so often discussed in the aesthetics literature) is that boredom doesn't merely block us from experiencing a work's potential aesthetic value. Its presence instead implies that there is none to be experienced. At the same time, boring artworks can, and often do, motivate the subject to explore and make sense of them. Successful boring artworks (Warhol's Empire, Beckett's Molloy, Béla Taar's Sátántangó, Basinski’s Disintegration Loops) afford the subject with a type of agency to seek meaning or interest in, or engagement with the artwork (either as an object or as an event) all the while the artwork itself stubbornly resists all of that (Elpidorou and Gibson in press). The role of boredom in art has been discussed before (e.g., Çağlayan 2016; Elpidorou 2017; Elpidorou and Gibson in press; Matravers 1995; Moller 2014). It is not the place here to summarize those works but many of the questions that Contesi brings up are explicitly addressed in them.

Let me conclude by briefly considering two additional issues that Contesi brings up in his discussion. In his concluding remarks, Contesi offers two reasons that are meant to show that "cases of art and real life come apart." (1) Emotional reactions to art (and not to life) come with a distancing effect (artworks keep negative affects at a psychological "distance" so that they don't become overwhelming and ultimately incompatible with possible enjoyment) (for a discussion of this effect, read Menninghaus et al. 2017). (2) The manner in which we come to appreciate the value of emotions in life differs from that in art. Ultimately, Contesi takes these two reasons to spell trouble for my position of Propelled. But they don't. As I already mentioned, nowhere do I hold that there is no difference between our emotional reactions to life and those to art. All the same, these two points are of inherent philosophical interest and thus deserve our attention, regardless of whether they pertain to the book or not.

To begin with, it is worth pointing out that it isn't always correct to state that art introduces a distancing effect. Strohl argues for this point convincingly with regards to agitation. He writes, "When one is agitated, the object of agitation is some nuisance, and it doesn't matter whether the nuisance is a fictional representation" (Strohl 2018, 2). I believe the same holds for boredom (Elpidorou and Gibson in press) and frustration. The fact that we are bored or frustrated by a fictional state of affairs, let's say, doesn't attenuate our boredom or frustration nor does it make the experience of such emotions less real. Perhaps this point is acknowledged by Contesi himself. His language is suggestive of the possibility that distancing isn't always a feature of our emotional responses to art. But if that is so, then the requirement of psychological distance can't be a necessary condition and thus doesn't deliver Contesi's conclusion. 
Now consider Contesi's second reason. He writes:

[T] he cases often discussed in the aesthetic literature are cases in which our appreciation of the value of an aesthetic experience occurs both consciously, and more or less simultaneously with, the experience itself. By contrast, Elpidorou's cases tend to be cases that one can only value retrospectively (or by means of an unusually keen consciousness).

I am doubly puzzled by this claim. First, maybe the examples that philosophers of aesthetics often adduce are ones that involve immediate emotional reactions (e.g., horror or disgust), but that doesn't mean that those are the only emotional reactions to art, nor does it entail that we can grasp the value of those experiences simultaneously with the experience itself. Consider, for instance, emotional reactions such as uneasiness, jadedness, dread, existential malaise, or despondency. These are possible reactions to artworks, but they don't always occur simultaneously with our experience of an artwork. A performance, a book, or a film might not immediately incite in us those reactions, but it might eventually-after thought, or further discussion and analysis. Moreover, even if we focus on emotional reactions that are more or less simultaneous with our experience of the artwork (e.g., horror in the case of watching a film), this feature, in and of itself, fails to show anything about how and when we appreciate their value. Experiencing an emotion is one thing; appreciating it is something else entirely.

Second, I am unclear as to why Contesi attributes to me the position that the cases that I discuss are "cases that one can only value retrospectively (or by means of an unusually keen consciousness)." I am assuming here that by "cases" Contesi means the examples that I provide in Propelled that are meant to illustrate the value of negative emotions. Yet nowhere in the book do I state that the value of negative emotions can be derived only retrospectively. Indeed, one of the aims of Propelled is to contribute to a type of psychological and emotional literacy with respect to boredom, frustration, and anticipation. So, when we experience these states, we can think about them and use them to our benefit. If that is what is meant by "unusually keen consciousness," then so be it. Note, however, that such an admission neither commits me to the claim that there is no important difference between emotions in real life and emotions in art nor to the claim that our appreciation of the value of emotions has to necessarily happen retrospectively. To read Propelled in this way is uncharitable.

\section{THE FRUSTRATION OF NON-REWARDS AND EFFORT: RESPONSE TO HARDCASTLE}

What is the affective nature of the experience of unexpected non-rewards? And how does it compare to the experience of an unexpected punishment or loss? Should both experiences be subsumed under the emotion type of frustration? Or are they distinct experiential states with different elicitors, concomitants, and outcomes? By considering and responding to these questions, Valerie Hardcastle objects to my explication of the emotional state of frustration. Her main objection amounts to the claim that I have misread what the scientific literature on unexpected outcomes reveals. On the basis of this alleged misreading, I've been operating, Hardcastle claims, with a "more expansive view of what 'frustration' means than what the common folk (or a technical philosopher) would allow." The upshot of Hardcastle's commentary is that what I call "frustration" in Propelled is not really frustration (Elpidorou 2020). Instead, it is a different affective state that is the product of an 
unexpected non-reward. A truly frustrating experience, for Hardcastle, is one that arises as the consequence of an unexpected punishment (or loss). Such an experience, however, cannot do the motivating work that I take frustration to be doing in Propelled. Or so Hardcastle claims.

I am indebted to Hardcastle for engaging with Propelled and for her insightful commentary. The questions and challenges that she presents concern the affective and volitional character of frustration and thus demand our attention-answers to them will contribute to our understanding of this important affective phenomenon. In what follows, I respond to Hardcastle's objections and show that my understanding of the emotion of frustration and use of "frustration" are thoroughly supported by the empirical literature. In fact, far from being a misunderstanding, the description of frustration given in Propelled appears to be the only tenable one.

\section{Could Unexpected Non-rewards Be Pleasurable?}

Before I turn to a presentation of Hardcastle's position, I wish to note one important point of agreement between the position that I advance in Propelled and Hardcastle's commentary. Hardcastle writes that "the internal sense of being on the receiving end of an unexpected non-reward is to feel challenged and to want to double-down on getting the reward for the behavior." This statement is the acceptance of a key claim that I make in Propelled. Obstacles, difficulties, or challenges_as long as they are perceived to be instances of unexpected non-rewards—can be valuable due to the fact that they are energizing and that they propel us toward the completion of important goals. The main disagreement between Hardcastle and the position in Propelled has to do with whether or not frustration is the experiential consequence of the perception of the occurrence of an unexpected non-reward. In simpler words, is unexpected non-reward the elicitor of frustration or not? I hold that it is. Hardcastle disagrees.

As I understand it, Hardcastle's position rests on three claims that, if true, jointly give rise to her conclusion. It can be summarized in the following premises-conclusion form:

P1: There's an important distinction between unexpected non-reward and unexpected punishment.

P2: Frustration is an aversive experience and essentially so.

P3: Only unexpected punishment is (or leads to an experience that is) aversive; unexpected non-reward is "not an aversive experience" (or does not lead to an experience that is aversive).

C: Unexpected non-reward is not (or it does not lead to) frustration.[2]

Premise 1 holds that there's an important distinction between unexpected non-reward (UnR) and unexpected punishment (UnP). I accept that this is so, but I am unclear as to what this distinction amounts. Is this a distinction that makes a difference in the case of frustration or not? Consider the following two options. (1) The distinction between $\mathrm{UnR}$ and $\mathrm{UnP}$ individuates between two distinct emotional experiences in the following way: frustration follows $\mathrm{UnP}$, but a different emotional state follows UnR. (2) UnR and UnP are different antecedents of the same emotional experience (frustration). Premise 1 is consistent with both options. In fact, it 
is even consistent with a third option: (3) Both $\mathrm{UnR}$ and $\mathrm{UnP}$ should be subsumed under a more general event type, and that type ought to be identified with frustration.

Hardcastle asserts (1). She writes that "these unexpected consequences are two different types of events that have different impacts on creatures, so we should probably call them by different names." But it is worth noting that Hardcastle's assertion opposes the classical definition of frustration, which adopts (3). Dollard and colleagues defined frustration as "an interference with the occurrence of an instigated goal-response" (Dollard et al. 1939, 7). This influential definition of frustration makes frustration an objective occurrence in the world. Furthermore, it is an expansive definition of frustration that groups $\mathrm{UnR}$ and $\mathrm{UnP}$ together. For the Yale group, any obstacle (be it unexpected punishment, loss, or non-reward) that blocks the attainment of some expected goal or gratification is frustration (read Berkowitz 1988, 1989).

I mention the classical definition of frustration not to recommend it, but to make clear that broad definitions of frustration have an important place in the literature on frustration. Still, in Propelled, I operate with a different understanding of frustration. I take frustration to be an emotional state (as opposed to a worldly event or happening) that antecedently depends on the presence of a set of appraisals about our situation. This shift in the understanding of frustration is not idiosyncratic to Propelled; it is rooted in and supported by the empirical literature. Indeed, since the influential work of Abraham Amsel (1958, 1992), frustration has been conceived as a psychological state and not as an objective event. So, it is open to Hardcastle to reject the classical definition of frustration and maintain that from a psychological perspective it makes a difference as to whether one is faced with UnR or UnP: it is only the latter that gives rise to frustration.

It is here where Premise 2 and Premise 3 come into play. Premise 2 states that aversive phenomenology is an essential property of frustration. If frustration is not necessarily aversive, then pointing out that the experience that follows from unexpected non-reward is not aversive does not prove that the experience isn't a token of frustration. Thus, in order for the conclusion to follow, Premise 2 must make an essentialist claim about frustration. I grant this claim. It is hard to conceive what frustration would be if it were to be experienced as non-aversive. Hence, the main point of contention lies with Premise 3. Contrary to what I claim in Propelled, the premise maintains that the experience of non-expected rewards is not aversive. Such a claim is also supposed to make my alleged misreading of frustration clear: according to Hardcastle, I take experiences of unexpected non-rewards to be frustrating, yet they are not. And they are not because they are not aversive.

\section{Frustrating Non-Rewards}

Is it correct to maintain that the experience of unexpected non-rewards is not aversive? Hardcastle doesn't cite any work that supports this crucial claim. Her remarks about QWOP are suggestive but they don't ultimately lend support to her position. In that context, she writes, "each time they [the players of the video game] achieve this goal [move the avatar], they get a psychological boost." But this observation doesn't show that the experience of an unexpected non-reward is pleasurable. It shows that getting a reward (moving the avatar, in the case of QWOP) after you failed to obtain the reward (in a previous attempt at the game) is pleasurable. The failure isn't what's pleasurable; it's the success after the failure that we enjoy. What is more, when discussing cases of chronic pain, Hardcastle grants that in some cases individuals may experience chronic pain as unexpected non-rewards. But when faced with the question whether this experience can be pleasurable or non-aversive, she notes that she "cannot say that patients who experience their chronic pain as a non-reward see 
it as something pleasurable." According to her own admission then, the experience of unexpected non-reward isn't necessarily pleasurable.

I think personal intuitions (mine, Hardcastle's, or someone else's) can only take us so far in resolving the main issue. To determine whether the experience of unexpected non-rewards is aversive or not we should look to the relevant empirical evidence. But before we do that, we ought to get clear on what exactly "unexpected non-rewards" means. [3] Without having a clear understanding of this type of experience in mind, we might be misunderstanding or even misappropriating available findings.

I understand the experience of an unexpected non-reward to be the experience of the omission of a reward (that is, the experience of not receiving something that one was expecting). My proposed understanding is a common one in the frustration literature. In turn, I do not believe that it contradicts Hardcastle's stated position in her commentary. To illustrate my point, consider what Hardcastle writes when discussing QWOP:

In QWOP, the reward for the gamers' playing is making the toy human move as they intended. Each time they achieve this goal, they get a small psychological boost. By their effort, they achieved what they were trying to do. But they are not successful every time they try. Sometimes, despite their best efforts, they get the non-reward of the virtual person falling down. The behavioral response is to double-down and try again. Small rewards coupled with unexpected non-rewards leads to persistence (Papini 2003, 2006).

In her discussion of unexpected non-rewards, Hardcastle cites Papini. But Papini follows Amsel and other researchers in understanding unexpected non-reward as omission of a reward. In his 2003 article, Papini writes:

The terminology used in the rest of the paper is derived from Amsel's [1992] frustration theory, developed explicitly to account for the behavioral effects of surprising nonreward (SN) in experimental situations. The term nonreward refers to the omission, reduction in magnitude, or quality degradation of an appetitive reinforcer (e.g., food, water). Nonreward is surprising if it occurs in the presence of signals previously paired with a reward of greater incentive value than the current one (84; emphasis added).

Hence, following frustration researchers we can take the experience of an unexpected non-reward to be the experience of the omission of a reward. Is such an experience aversive or not? When we turn our attention to the literature, I can't find any evidence that justifies the claim that it is not aversive. On the contrary, available evidence speaks in favor of the contrary claim. Consider the following:

i. The affective quality of the experience of unexpected non-rewards is routinely labelled "aversive" by researchers and is identified with frustration. Abler and colleagues, for instance, state that "as anyone knows, the omission of a reward can lead not only to behavioural changes and learning but, usually, also to emotional distress called frustration" (Abler et al. 2005, 671). In his review of the neuroscience of frustration, Yu notes that " $[\mathrm{r}]$ eward omission or reward blockage is one major elicitor of frustration" (Yu 2016, 223). In a theoretical overview of frustration, Jeronimus and Laceulle write that " $\mathrm{t}]$ he most reliable trigger of frustration is an externally attributed omission of a rewarding event or item, and especially a perceived obstruction by an intentional antagonistic agent" (Jeronimus and Laceulle 2017, 
1). Similar claims can be also found in Bierzynska et al. (2016), Dixon et al. (2013), and Deveney et al. (2013); but read also Buss (1961, ch. 2).

ii. Subjects experiencing unexpected non-rewards exhibit behavioral changes suggestive of undergoing an aversive experience (e.g., Yu et al. 2014; Dixon et al. 2013; Otis and Ley, 1993).

iii. There's neurological evidence in humans that suggests that the experience of an omission of a reward is aversive. For the most comprehensive review available, read Yu (2016).

iv. Numerous studies involving animals show that surprising non-reward leads to an aversive experience. See, e.g., Do-Monte et al. (2017), Papini (2003), and Papini and Dudley (1997).

This isn't the place to offer an exhaustive review of the literature on frustration and unexpected non-rewards. All the same, the aforementioned evidence opposes, strongly I believe, the claim that the experience of unexpected non-rewards is not aversive. The evidence also rejects the contention that such an experience shouldn't be labeled "frustrating." Consequently, the claim made in Propelled that the experience of unexpected non-rewards is aversive isn't merely consistent with the empirical literature on frustration, but also robustly supported by it.

Having said that, it is important to acknowledge that Hardcastle might ultimately be using a different understanding of "unexpected non-rewards," one that does not refer to the experience of the omission of a reward. What could that understanding be? Using the example of QWOP-a video game in which the player controls the movements of an avatar by using only the Q, W, O, and P keys of the keyboard-we could say that unexpected non-reward is the experience of unexpectedly receiving a non-reward and not the experience of the omission of a reward. Perhaps this is what Hardcastle means when she states that the player of QWOP "get[s] the non-reward of the virtual person falling down." When one plays the game and fails, one does not fail to receive a reward but receives instead a non-reward (a penalty).[4]

I would like to make two comments in response to the aforementioned explication of "unexpected non-rewards." First, a specific point about QWOP: I am not convinced that in the case of QWOP, the failure to move the avatar forward is interpreted by the player as a penalty instead of the omission of a reward. The game is structured so that the aim of the player is to make the avatar move as far as possible, and ultimately to cross the finish line. The player's expectation thus, at least after the player has played the game a few times, is that one succeeds in the game if one is able to move the avatar farther than it had moved before. Stated otherwise, given the difficulty of the game, success in the game doesn't necessarily mean crossing the finish line. Rather, success is progress: doing better than before or marking a new personal record. Consequently, when the avatar falls down during a run, this may or may not indicate a failure. It is a failure if the avatar fails to advance beyond one's previously best distance. What this understanding of the game suggests is that a failed run might involve a violation of an expectation: one did worse than what one had hoped. As a result, a failure in QWOP could be understood as indicative of the lack of a fulfillment of a goal, and a goal in a video game is a type of reward. Thus, there is a way of making sense of what goes on in QWOP that is in line with the understanding of unexpected non-rewards that I explicate here and in Propelled. When one fails in QWOP one experiences the omission of an expected (or hoped for) reward (i.e., a new personal best record). 
Second, and regardless of whether there are multiple ways of understanding "unexpected non-rewards," I do not think that any crucial claims of Propelled are threatened by allowing the possibility that unexpected non-rewards could sometimes mean something other than "failure to receive an expected reward." Many of the examples that I give in Propelled are examples of cases in which one fails to receive an expected reward, and, as I indicated above, empirical evidence strongly suggests that the phenomenological character of such an experience is indeed aversive.

\section{The Emotional Complexity of Effort}

Before concluding, I would like to raise two final points. When discussing effort, Hardcastle writes that, "Elpidorou is entirely correct when he claims that we associate effort with value (108). However, he is incorrect that effort is unpleasant or unrewarding. Indeed, for many it is exactly the opposite." I was somewhat surprised by this assessment of effort and reading of my position. There's an important difference, I believe, between being rewarding and being pleasant, and although I accept that effort can be the former, I don't accept, at least not without important qualifications, that it can be the latter.

Effort can be rewarding insofar as it leads to certain desirable outcomes-in that respect, it can be valuable, beneficial, productive, illuminating, or enriching. Indeed, given its ability to confer a sense of meaningfulness and purpose to our lives (Elpidorou 2020, chap. 7), effort appears to be rewarding precisely in that sense. All the same, I don't think that effort is, in and of itself, pleasurable. The claim that effort is itself pleasurable runs in the face of studies that show that both physical and mental effort are aversive (See, e.g., Inzlicht, Shenhav, and Olivola, 2018; Kurzban 2016; Kurzban et al. 2013). In light of these findings, one might claim, and perhaps Hardcastle's comments could be read in this way, that effort isn't solely aversive. In other words, even though there might be an important aversive component to effort, such a component doesn't exhaust the experience of effort. I don't deny this reading of the phenomenology of effort. Still, it is important to note that whatever pleasure we may find in effort is not what we might call "sensory pleasure" - to wit, effort doesn't feel pleasurable in the way that activities such as eating a decadent dessert, having sex, or doing drugs feel. The pleasure that effort involves is a more cognitive (for a lack of a better term) pleasure-it is the type of pleasure or satisfaction that we derive on the basis of the fact that we have undergone a difficult experience. (Sometimes psychologists call this type of pleasure "accomplishment pleasure"; Rozin 1999). That is to say, if there is pleasure in effort, it exists in virtue of the fact that effort is experienced as aversive. So, the presence of a cognitive pleasure or a sense of worth that we might derive from effort doesn't vitiate the aversiveness of effort. Rather, it makes us appreciate the aversiveness of effort more and calls upon us to grasp more clearly its distinctive role in our lives.

This interplay between, on the one hand, hardships and aversive experiences, and, on the other hand, reward, value, and accomplishment pleasure derived from effortful experiences, leads me to my final point. Studies show that our lives are thoroughly emotional: we experience many different emotions, and we experience them often (Myrtek, Zanda, and Aschenbrenner 2001; Wilhelm et al. 2001). Moreover, many situations can elicit mixed emotions: they bring about the simultaneous (or near simultaneous) co-occurrences of positive and negative affective states (Larsen et al. 2017). Indeed, as it was shown by a study by Trampe and colleagues, about 33\% of the time individuals experience at least one positive and one negative emotion simultaneously (Trampe, Quoidbach, and Taquet 2015). Hence, when considering real life stories (e.g., Andrew Wiles' discovery of Fermat's last theorem), we should be mindful of the complexity of our emotional lives. Wiles didn't just 
experience frustration. Indeed, it is rare to experience just one emotion at a time; our emotional lives are not "monochromatic" in that way. Instead, he experienced a whole array of emotional states, some positive and some negative-e.g., the frustration of being stuck but also the joy of finding meaning and purpose. Once again, such a realization doesn't speak against the claim that the experiences of effort and frustration are aversive. The positivity that we derive from struggle doesn't render its aversiveness any less real.

In sum, given what the literature on frustration reveals, I maintain that what I called "frustration" in Propelled is real frustration: it is both our everyday experience elicited by the realization that an obstacle is blocking the achievement of an important goal and the affective phenomenon studied by many psychologists and neuroscientists.

\title{
THE EMOTIONAL APPROPRIATENESS AND VALUE OF BOREDOM: A RESPONSE TO PISMENNY
}

\begin{abstract}
A Triad, Not a Trinity
Propelled focuses on a triad of psychological states: boredom, frustration, and anticipation. But why those three states and not some others? What is the relationship between them? How do they come together? And how do they relate to the good life? In the first part of her commentary, Arina Pismenny raises these questions. She is right to do so and I'm grateful for the opportunity to address them.
\end{abstract}

There are two main theoretical reasons why Propelled groups these three states together. The first has to do with how they transform our relationship to the present; the second has to do with how they relate to self-regulation.

To begin with, in all three states, the now fails to fully satisfy us. This is obvious in the case of boredom. Be it because of a perceived meaninglessness (Van Tilburg and Igou 2011, 2012), an inability to pay attention (Eastwood et al. 2012), or the realization that our situation is either non-optimally challenging (too easy or too difficult) (Csikszentmihalyi 1975; Daschmann et al. 2011) or unnecessarily constraining (Caldwell et al., 1999; Martin et al. 2006; Steinberger et al. 2016; van Hooft and van Hooff, 2018), the result is the same. In a state of boredom, we find ourselves in an experientially unpleasant state from which we seek escape. The same holds for frustration, albeit for different reasons. The experience of frustration signifies the presence of a bothersome obstacle and a thwarted desire. And so, as long as we remain frustrated, we are painfully aware that there is something that is blocking the fulfillment of an important goal. If boredom is a call to move out of our current unsatisfactory situation, frustration is a call to work through our discontent with the hopes of rendering our situation congruent with our goals (read Yu 2016). What about anticipation? It also changes our relationship to our current situation. Whether we anticipate with excitement, with dread, or even with mild indifference characteristic of everyday mind wandering, we have lost our "touch" with our current task. Our present during anticipation fails to engross us. We are mentally somewhere else. What is more, there is even a type of anticipation that doesn't just disconnect us from our present but demotes it. This is a common experience and takes place when we look forward, excitedly and impatiently, to some future event-the end of a shift, a sunny vacation, a hard-won promotion, or the end of the pandemic. Such an anticipatory state, just like boredom and frustration, signals a dissatisfaction with our present. When we anticipate in such a fashion, the present dissatisfies us-we don't want it but something else; we don't enjoy it but endure it. All three states, thus, reveal 
to us how our desires are faring. They forcefully point out to us a disconnect between what we wish to have and what we currently have.

The second reason for grouping together these three states concerns their ability to motivate us. They help us to get from one state to another. Boredom takes us from a state of dissatisfaction and perceived meaninglessness to one that is hopefully both satisfactory and meaningful to us. Frustration either gives us the energy that we need to keep pursuing our goals or forces us to give up on unattainable goals. Finally, anticipation gives us a clear view of the future. It allows us to define ourselves and in doing so, helps us to choose how to act in the present so that we can bring about the realization of our desired goals and projects. As I argue in the last chapter of Propelled, recent work in the psychology of self-regulation (read, e.g., Kruglanski, Chernikova, and Jasko 2018; Kruglanski et al. 2013) offers us with good reasons to think that being able to initiate movement is vital both to hedonistic and eudaimonistic well-being. Hence, through their capacity to move us, these three psychological states become elements of well-being.

It is, of course, right to claim, as Pismenny does, that these states "require the agent to take the right attitude towards them to overcome their potentially harmful effects.” All the same, such a realization doesn't abolish their potential role in the good life. Emotions and other psychological states don't typically make our lives better on their own and without our guidance. Anger may prompt us to rectify a perceived injustice or to overreact. Fear can protect us from danger or foreclose important possibilities for growth. Boredom could push us to act pro-socially and to enhance creativity, but it may also give rise to maladaptive and destructive actions. The outcomes of our psychological states are many and varied and straddle the line between good and bad, beneficial and harmful. By knowing the potentially harmful outcomes of our psychological states we stand a chance of preventing them. By knowing the ways in which they can help us, we can use them to move us closer to the completion of our goals. Propelled is a guide into the uses and abuses of boredom, frustration, and anticipation.[6]

There's something else. There's one last reason as to why this particular triad was chosen. This isn't a theoretical reason but a personal one. The choice of these three states reflects my interests (philosophical or otherwise), background knowledge, and goals. One often writes on a topic that one finds genuinely interesting and wishes to explore. I did the same. The choice of these three states isn't an argument that these states are more worthy of our consideration than some other states, nor is it proof that they necessarily have to be considered as a triad. Boredom, frustration, and anticipation form a meaningful triad but not a holy trinity. Perhaps a different book could have been written by focusing only on boredom and frustration, leaving anticipation on the side. Still, I do think that anticipation is an important element of many of our emotional states. The value of anticipation doesn't depend on whether it is affectively laden or not. What is crucial about anticipation is that it offers us a view of the future-it makes us realize what is interesting and meaningful to us and structures our goals and comportment to the world. Indeed, without anticipation it is hard to see what kind of positive contribution boredom and frustration would do. Without anticipating a better state, the motivational potential of boredom would decrease-what's the point of struggling to escape the grasp of boredom if we don't know what else to do? And without anticipation, frustration might not even arise. Frustration requires clearly defined goals and expected outcomes, both of which appear to be the products of anticipation. 


\section{Boredom As An Emotion: A Working Hypothesis}

Is boredom an emotion or some other affective state, perhaps a mood, a drive, a sensation, or an attitude of some kind? In the second part of her commentary, Pismenny takes up the issue of the ontology of boredom. She addresses the question of what the formal object of boredom might be and after considering four possible elucidations of the character of this object, she argues that none of them allows us to specify aptness conditions for boredom. Pismenny thus concludes that because we are unable to specify such conditions we should reject (or at least be critical of) the claim that boredom is an emotional state.

There is a lot to be said in response to this excellent and difficult question. In this and the following section, my intention is to defend the claim that boredom should be understood as an emotion. However, before I turn to my defense, it is important to raise the following two points. First, the precise nature of boredom ought to be the result of not just conceptual analysis but also of empirical work. Consequently, I don't take my claim that boredom is an emotion to be an established, non-revisable claim. I submit the claim as the conclusion of an inductive argument: the assessment that boredom is an emotion offers, I believe, the best explanation of the available evidence. Second, much of what I say in Propelled about boredom doesn't require that we have a settled account of its ontological character. My claims about boredom's role in the good life depend on two key characteristics of boredom: that it marks a state of dissatisfaction and that it involves a desire to escape that which gives rise to our dissatisfaction. As long as those theses are true-and given that they are thoroughly supported by empirical findings, I see no reason to doubt them-the role that I assign to boredom in Propelled (or something close to that) should be accepted, regardless of boredom's ontological status.

Having said that, I think that we can and should defend the claim that boredom is an emotion. Consider, for instance, the following four reasons in support of this assessment. First, boredom is routinely taken by researchers to be an emotion (e.g., Bench and Lench 2013; Fisher 1993; Pekrun et al. 2010; Van Tilburg and Igou 2017; Westgate and Wilson 2018). Obviously, this treatment of boredom doesn't amount to a decisive argument in support of the conclusion that boredom is an emotion. The treatment, however, does reveal that the view that boredom is an emotion is a working hypothesis that has proven to be remarkably useful. For instance, it allowed researchers to make great progress in elucidating the causal antecedents of boredom, analyzing its cognitive components, and determining boredom's physiological correlates. Importantly, the working hypothesis has also allowed researchers to show the ways in which boredom can be individuated from other emotional states like frustration, sadness, and anger.

Second, the claim that boredom is an emotion fits well with a pre-theoretical and commonly held fourfold division of episodic affective phenomena. It is customary to place episodic affective phenomena in one of the following four categories: (i) drives or instincts; (ii) bodily sensations or feelings; (iii) moods; and (iv) emotions. Known findings about boredom's antecedents, outcomes, and concomitants speak against placing it in (i)-(iii). Boredom requires a cognitive basis (typically an occurrent belief or perception about our situation and perhaps even about ourselves; e.g., Van Tilburg and Igou 2012; and Eastwood et al. 2012), has a well-defined intentional object (we are often bored with this or that particular task, book, conversation, song, etc.), and is "malleable" insofar as our experience of boredom can be affected (intensified, alleviated, or altered) by our beliefs, perceptions, or cognitive processes. Drives, instincts, sensations, or feelings typically don't require a cognitive basis. Moods lack a specific intentional object.[5] And all aforementioned affective phenomena with the 
exception of emotions don't appear to be malleable (or as malleable as boredom). (I discuss the different possible types of boredom in my response to Gallegos. For a proposed taxonomy of boredom, read Elpidorou 2022.)

Third, boredom fits the general characterization of emotions that is given in the affective sciences (Scherer 2005). Just like other emotions, boredom is a relatively short-lived, flexible, multi-dimensional response to specific physical and social situations. It is initiated by an individual's appraisal of an event that bears some kind of personal significance to the individual and leads to a cascade of interrelated responses in the individual. For a defense of this claim, read Elpidorou 2018a.

Fourth and last, the hypothesis that boredom is an emotion is consistent with various philosophical theories of the ontology of emotions. Given the important role of appraisals in boredom, one could argue that boredom is the evaluative judgment that something is uninteresting, meaningless, or unengaging. Given its volitional character, one could argue that boredom is a belief-desire combination: e.g., it is the combination of the belief that this is uninteresting and the desire that I want to do something else. Or given boredom's action readiness, one could argue that boredom is an embodied evaluative attitude towards situations, objects, or individuals. Following the attitudinal theory of emotions (Deonna and Teroni 2015), we might say that boredom is evaluative because it consists in feeling the body's readiness to act so as to disengage with one's current situation and to engage with an alternative situation.

In light of these considerations, we are justified, I believe, to operate under the (revisable and falsifiable) assumption that boredom is an emotion.

\section{The (In)Appropriateness of Boredom}

But then what about Pismenny's claim that it is difficult (if not impossible) to specify boredom's aptness conditions? This is an important challenge and one that should be addressed-here, but also more fully in some other work. I offer two responses to Pismenny's challenge. First, I suggest that one of the specifications of the formal object of boredom that Pismenny considers but ultimately rejects shouldn't be ruled out. Second, I present a theoretical characterization of boredom that treats it to be a cognitive phenomenon intimately related to attentional difficulties and I argue that such an account of boredom allows us to specify its aptness conditions.

Pismenny suggests that one possible way of elucidating the formal object of boredom is by offering a "causal account." According to this proposal, boredom's formal object (and in fact, its representational character) could be "cashed out in terms of whatever produces the emotional reaction in question." Yet after introducing this possible approach, she quickly rejects it. She writes:

[W] should expect that boredom has representational content, which in turn requires that it is subject to correctness conditions. If this is right, then the causal account will fail to demarcate the boring. In order for boredom to have representational content it must be possible in principle for it to misfire or misrepresent.

If Pismenny is correct, then it must be impossible for a causal account to explain how boredom comes to represent and misrepresent its objects (both particular and formal). I say "impossible" and not "difficult" 
because what is needed in order for the conclusion to go through is a demonstration that the causal account (in its many variants) cannot succeed. However, if this is a premise in Pismenny's objection, then we are owed an account of the presumed fatal faults of the causal account of the representational character of boredom.

The problem with the causal account of boredom might lie with the fact that it is causal (or correlational, developmental, or evolutionary; causal accounts of representation are a family of related approaches [Adams and Aizawa 2017]). If that's the case, then Pismenny's argument is a far-reaching one. It doesn't apply just to the emotional state of boredom, but presumably to any account of any representational state that aims to explain its intentional relationship through some kind of causal (or correlational, developmental, or evolutionary) mechanism. I don't deny that there are serious difficulties with efforts to naturalize mental content and representation (Mendelovici and Bourget 2014). However, such difficulties appear to be par for the course with any attempt to reduce intentionality to a completely natural phenomenon. Despite their troubles, causal accounts of representation do continue to constitute a productive and promising research program in philosophy and the cognitive sciences. Thus, unless it is shown that causal accounts are deeply and irredeemably problematic it seems premature to declare that a causal account of boredom's representational content cannot be provided (read e.g., Dretske 1995; Fodor 1990, 1994; Millikan 1989, 2004, Neander 2017; Neander and Schulte 2020; Papineau 1987, 1998).

But Pismenny's objection could be read in a more qualified way. The problem that Pismenny points out, one might hold, isn't with the fact that causal accounts are causal (in a broad sense), but with the specific application of the causal account to boredom. But if accounts of representational content qua causal accounts aren't faulty beyond repair, then why can't they be used to ground the intentional relationship that is meant to hold between boredom and its formal object? Other emotion researchers have utilized them to explain emotions' representational character (read, e.g., Prinz 2004). So, boredom theorists can try too. For instance, one might suggest that if boredom reliably co-varies with the presence of some environmental conditions because it was designed to do so through evolutionary pressures, then boredom would be apt if it arises when those environmental conditions are present and inapt if it arises when they are absent.

I realize of course that my brief and promissory comments on the causal account of mental representation don't make much progress in elucidating the formal object of boredom. So, it is legitimate for one to still wonder what the formal object of boredom might be. In the case of boredom, the issue of its formal object is complicated by the fact that there is currently no widely accepted theory of boredom. Is boredom essentially an affective, volitional, or cognitive phenomenon? Are some aspects of boredom (attentional difficulties, perceived meaninglessness, altered perception of the passage of time, an urge to escape boredom, or an appraisal that one's situation is unsatisfactory) more fundamental than others? Could there even be different types of boredom? It is not the place to discuss these debates here. I mention them only to grant myself license to focus on just one account of boredom: the attentional theory of boredom.[7]

According to the attentional theory, boredom is "the aversive state of wanting, but being unable, to engage in satisfying activity" (Eastwood et al. 2012, 483). Boredom arises when the following conditions are met: (a) We are unable to successfully and satisfactorily engage our attention; (b) we are aware of the fact that we cannot successfully and satisfactorily engage our attention; and (c) we "attribute the cause of our aversive state [boredom] to the environment" (Eastwood et al. 2012, 484). 
Using this account of boredom, we can then maintain that the formal object of boredom is the cognitively unengaging. Although the particular objects of boredom can be many (a book, a Netflix show, a conversation, a town, a frenemy), they are objects of boredom because they are represented as cognitively unengaging. Could this account of the formal object of boredom allow us to specify its aptness conditions? I don't see why not. Under the proposed attentional account, boredom would be appropriate (or fitting) when (a)-(c) hold and we are correct in attributing the cause of our boredom to the environment. An experience of boredom would turn out to be inappropriate if (a)-(c) hold, but we are wrong to attribute the cause of our boredom to the environment.

We can discern the aptness of boredom when we consider our interactions with repetitive or monotonous stimuli. Although such stimuli don't guarantee the experience of boredom, they are often reliable causes of boredom. Indeed, it is reasonable for someone to experience boredom when they are exposed to monotony or repetition. The same goes for engagement with tasks that are too easy for us or that place upon us unreasonable constraints. In such situations, it is again reasonable and appropriate for an individual to experience boredom. One's inability to engage with their situation makes sense and it is justified given the environmental features.

On the contrary, there will be cases in which the experience of boredom would turn out to be inappropriate or inapt. In fact, it is not untypical for us to criticize others when they (unjustifiably to our minds) complain of boredom. We often chastise children when they experience boredom while being immersed in an environment filled with opportunities for engagement. Or we might tell students that they shouldn't be bored with a particular class. We might ask them to cognitively reappraise the class, remind them of its benefits, ask them to pay attention, or point out to them the ways in which the lecture or material is interesting, engaging, stimulating, etc. - we do all that because we take their emotional experience to be inappropriate and want to correct it. Such attitudes, I believe, are indications that boredom is subject to aptness conditions.[8]

\section{THINKING ABOUT DEEP BOREDOM: A RESPONSE TO GALLEGOS}

Suppose that we are considering an emotion type $E-E$ can be sadness, disgust, boredom, anger, or some other emotion. Are there tokens of that emotion type that are "deeper" than others? And if this notion of emotional depth is both coherent and phenomenologically accurate, does it affect the character of our emotional experience? In his wonderfully rich and insightful commentary, Francisco Gallegos takes up these and other questions. By drawing upon the phenomenological work of Martin Heidegger, Gallegos focuses on the affective experience of boredom and distinguishes between ordinary (or simple) boredom and deep (or "profound") boredom. The former type of boredom corresponds to our everyday experience of boredom and thus to the boredom with which much of Propelled is concerned (Elpidorou 2020). It is unpleasant, transitory, and situationally dependent; it renders our tasks and situations meaningless, uninteresting, or unengaging; and carries motivational force insofar as it prompts us to escape the situation that elicited it. In analyzing this type of boredom, Gallegos argues that its unpleasantness and motivational force are connected to and explained by the fact that, during an experience of boredom, the manner in which we engage with the world becomes altered. "What makes such boredom unpleasant," Gallegos writes, "is the dissonance between the interpretive framework associated with our boredom and the other frameworks through which we are simultaneously 
experiencing the things and situations we are encountering." He adds: "In such moments, things show up as somehow both personally meaningful and personally meaningless." The perceived tension in how we relate to our personal projects makes the state of the boredom "uncomfortable;" the desire to resolve the tension grants it its motivational potential.

According to one reading, Gallegos' comments don't seem to be specific to boredom. Any emotional experience capable of giving rise to a "dissonance" between how things are presented through that emotion and how things are revealed through a different mode of relating to the world should have the same result. However, one could point out that what's distinctive about boredom is the fact that boredom (and perhaps only boredom) reveals a tension in perceived meaninglessness/meaningfulness. As recent empirical work reveals, during the experience of (ordinary) boredom, our current task or situation strikes us as meaningless (Van Tilburg and Igou, 2011, 2017). Such a realization is uncomfortable and painful because we are motivated to resolve it by seeking an alternative form of engagement that is itself meaningful (Moynihan, Igou, and Van Tilburg 2020). Gallegos' remarks about ordinary boredom are thus consistent both with the view that I offer in Propelled and with empirical findings explicating the relationship between perceived meaninglessness and boredom.

Gallegos has more to say, however, about deep boredom and it is these remarks that may mark a potential disagreement between his view and the position in Propelled. Gallegos notes that deep boredom is distinguished from ordinary boredom in two important respects: first, it is less aversive than ordinary boredom; second, it is weakly, as opposed to strongly, propulsive. Gallegos then sets out to explain these two features of deep boredom by an appeal to emotional depth and to the emotional or interpretative context that makes such a type of boredom possible. Gallegos concludes that "boredom is not inherently propulsive, but, rather, the propulsive quality of boredom is made possible by the emotional context in which an experience of boredom is located." If the motivational character of boredom depends on context, then not all occurrences of boredom will have the ability to do the work that I assign to boredom in Propelled. I concede this point. It would be foolish to make an unqualified claim about all possible experiences of boredom-in fact, in Propelled I'm careful to distinguish between state boredom and trait boredom (or boredom proneness), and only the former is capable of propelling us into a better state and thus having a potential positive role in our well-being. Nevertheless, Gallegos' remarks about deep boredom and emotional depth are important in their own right, independently of whether and how they relate to claims in Propelled. Because of that, I will examine how deep boredom relates to ordinary boredom and whether deep (Heideggerian) boredom is a form of boredom or not. Lastly, I will consider whether the functional view of boredom can account for the features of deep boredom that Gallegos singles out.

\section{Deep Emotions and Profound Boredom}

What does it mean to say that one emotional experience is deeper than another? Following Gallegos's discussion of boredom we might say that an emotional experience becomes deep when "a profound change takes place in the person's experience, as an entire category of evaluative properties suddenly disappears from their experience-namely, those evaluative properties that depend on one's sense of being a unique individual with distinctive commitments and concerns." Although this description is given in the context of profound boredom, it appears that a "disappearance" of a whole class of evaluative properties is something that might be shared by many deep emotions. For instance, Gallegos writes that "when we experience deep boredom, we can no longer make sense of how the things around us are relevant to the personally meaningful projects that normally allows us to become absorbedly engaged in activities." But couldn't this fundamental change in our 
comportment to the world occur regardless of the particular flavor of our emotional attunement? Wouldn't depression, deep sadness, or profound frustration have the same result?

In the case of boredom, the disappearance of self-defining qualities could relate to a change in the scope of boredom's intentional object. Accordingly, we might say that a token of boredom, $B 1$, is deeper than a different token, $B 2$, if the intentional object of $B 1$ is broader than the intentional object of $B 2$. Being bored with one's job is a deeper boredom than being bored with a particular task that one has to perform as part of one's job. And being bored with one's life is an even deeper sense of boredom. Life boredom seems to be a state (or condition) in which one fails to make sense of oneself and of one's involvement in one's projects. Moreover, such a thoroughly boring existence could function as "an interpretive framework" through which one's self, the world, and relationship to others becomes changed (Bardgdill 2000; Maltsberger 2000). Perhaps then the deep boredom that Heidegger discusses is a limiting case of this type of boredom: everything becomes boring for us-not just our present tasks and commitments, but crucially also our past and future projects.

Yet Heidegger's construal of profound boredom doesn't correspond to the phenomenon that either laypeople or scientists call "boredom." Heidegger's deep boredom is not ordinary boredom. The former is totalizing insofar as it affects every aspect of our existence and renders us an "undifferentiated no one" (Heidegger 1995, 135). The latter is not. Ordinary boredom lacks the comprehensive scope of profound boredom. Its emergence depends on our situation and can be alleviated often easily and by a mere change in situation. Moreover, profound boredom is a mood-a Grundstimmung, to be exact-and arguably the condition for the possibility of ordinary, intentionally "pointed," affective states, such as ordinary boredom. Finally, profound boredom is supposed to carry with it existential and philosophical import: for Heidegger, it reveals to us the nature of human existence and can prepare us for metaphysical thinking. Ordinary boredom does not.

There is another conception of boredom that is available to us that isn't ordinary boredom. In the empirical literature on boredom, it is customary to distinguish between state boredom (what I called above "ordinary boredom") and trait boredom (Farmer and Sundberg 1986; Fahlman et al. 2013; Neu 1998; Todman 2003). Trait boredom is a personality trait capable of transforming in profound ways an individual's relationship to themselves, others, and the world. Consequently, trait boredom appears to be, just like profound boredom, totalizing. It may even be ontologically informative. By rendering our existence uninteresting, meaningless, unengaging, or foreign, trait boredom may reveal to us the groundlessness of our existence.

All the same, trait boredom isn't Heidegger's profound boredom. For one, trait boredom is a personality trait, and as such it marks and predicts individual differences: some individuals possess this trait whereas others lack it. Thus, whatever the affective, cognitive, or motivational outcomes of trait boredom may be, they won't be experienced by everyone. On the contrary, profound boredom does appear to be something that can be experienced by everyone. Profound boredom, Heidegger tells us, "is rooted in time-in the time that we ourselves are" (Heidegger 1995, 133). As such, it emerges out of the most fundamental feature of human existence-namely, our care structure. Profound boredom is therefore supposed to be ontologically deeper than trait boredom and identifying the two would, for Heidegger, result in the conflation of two levels that ought to be kept separate-the psychological/biological and the ontological.[9] 
Lastly, trait boredom stands as an obstacle to an authentic existence (Elpidorou 2017). True, individuals characterized by trait boredom might experience the total withdrawal of being and possibilities described by Heidegger. Yet, such a withdrawal is not motivating (weakly or otherwise). Its presence is correlated with a host of harmful conditions and maladaptive behaviors (Vodanovich 2003; Vodanovich and Watt 2016) and is characterized by a profound lack of care (Bargdill 2000). Such features of trait boredom reveal that trait boredom doesn't afford the type of self-understanding described by Heidegger and which is assumed to take place during profound boredom.

We are forced to conclude, I believe, that profound boredom is something different than both our ordinary, everyday boredom and the boredom that has been the subject of numerous scientific studies (read also Elpidorou and Freeman 2019). The conclusion won't surprise those who are well versed in Heidegger. On the one hand, even though Heidegger uses ordinary terms in his works, he routinely appropriates them for his own purposes. Thus, the use of “boredom” doesn't entail that Heidegger is talking about ordinary boredom. On the other hand, Heidegger's fundamental ontology is not, nor can be reduced to, science. If profound boredom is a genuine phenomenon, then it won't be fully accessible through a scientific lens and the constructs of ordinary (or state) and trait boredom.

\section{Functional Boredom and Deep Boredom}

Regardless of how we settle the relationship between profound boredom and boredom (ordinary, trait boredom, or some other type of boredom), deep boredom deserves further attention. After all, deep boredom need not be identified with profound (Heideggerian) boredom-Heidegger's phenomenological analysis of profound boredom is just one possible explication of deep boredom. For that reason, I will conclude by considering what the functional view of boredom that I support predicts about deep boredom. Specifically, does the functional account agree with Gallegos' contention that deep boredom is both less motivating and less aversive than ordinary boredom?

The functional view identifies boredom with a specific role within our behavioral and mental economy (Elpidorou 2014, 2018b). It holds that boredom is an attempted transition from an input state to an output state. It arises when we find ourselves in a meaningless, uninteresting, non-stimulating, or overly stimulating situation. It reflects a dissatisfaction with our situation and can help us move out of our current state of discontent and into one that is either in line with our interests and values or engaging and stimulating in the right way. Boredom is a mechanism for action, a call to move when we've become stuck.

Suppose that ordinary boredom becomes deep. We are bored not with this or that task, but with all tasks, current and even future ones. If boredom becomes totalizing in this manner, then its motivational character will be affected. According to the functional view, boredom is meant to move us. Yet the movement that it instigates has a specific direction. That is to say, boredom doesn't prompt change for the sake of change-after all, the bored subject doesn't want to move from one boring situation to another. Instead, boredom prompts a change that will lead the emoting agent into a new state that isn't (or doesn't appear to be) boring. But if boredom turns deep, no situation will meet this requirement. There's nothing that will alleviate one's boredom, for everything appears to the agent to be boring. Under such conditions, the functional view predicts that the motivational force of deep boredom will greatly attenuate; perhaps it would even altogether disappear. When the agent comes 
to realize that escape from deep boredom is futile because everything is boring, the agent should lose their motivation to seek escape from deep boredom.[10]

The functional view also predicts that deep boredom will eventually evolve (or devolve) into something that isn't ordinary boredom. A key characteristic of boredom is the fact that it involves a strong desire to do something else. Such a claim about the character of boredom is supported by empirical investigations into what it is like to experience boredom (Chan et al. 2018; Van Tilburg and Igou 2011, 2012, 2017) and is an integral part of how boredom is defined (Eastwood et al. 2013) and operationalized (Fahlman et al. 2013). What is more, the functional view of boredom requires that boredom involves a volitional component and so in the absence of a desire for escape, boredom would cease to be boredom (Bench and Lench 2013; Elpidorou 2018a, 2018b). Indeed, this conclusion is consistent with studies that explored the ways in which boredom differs from apathy (Goldberg et al. 2011; Nisbet 1982). Therefore, if deep boredom is characterized by motivational loss, as I argued above, then the functional view entails that deep boredom is no longer ordinary boredom. It has changed into something else.

What would then happen to boredom's affective quality as it becomes deeper and deeper? Without a doubt, it would be transformed. What it is like to be in a situation from which escape is possible (ordinary boredom) is very different than what it is like to be in a situation from which escape is impossible (deep boredom). But would the experience of deep boredom be less aversive than that of ordinary boredom? I don't have the answer to this question. In fact, I am not even sure if the question itself is answerable. Aren't there many ways in which an experience can be said to be aversive? Consider pain, disgust, sadness, shame, anger, rage, frustration, depression, or existential ennui. They are all aversive experiences, but they are not all aversive in the same way. Being aversive doesn't appear to be a unitary notion or construct. Because of that a comparison between ordinary and deep boredom might not be possible. But even if it is possible, the comparison no longer appears to be very informative. From the functional perspective, deep boredom isn't a more or less extreme form of ordinary boredom. It is a different state altogether. 


\section{Notes}

[1] Contesi notes that "the emphasis of motion, or movement, has the consequence of neglecting activity that is less physical and more, say psychological." Such a description doesn't accurately capture my understanding of motion. As I make clear in Chapter 5 (especially, 68) and in my discussion of locomotion and self-regulation (155-7), "motion" doesn't refer simply to physical movement. "Motion" means any change from one state to another (be it physical or psychological). On page 156, I address this point explicitly when I state: “It's important to note that locomotion isn't characterized by a specific end state but rather by movement itself, where movement is understood to be any change from one state (psychological or physical) to another.”

[2] An alternative way of presenting Hardcastle's position is to focus on the behavioral consequences of unexpected non-rewards and show that they differ from those of unexpected punishments. The idea here would be to hold (a) that only unexpected non-rewards (and not unexpected punishments) are capable of motivating an agent to persist towards the completion of a desired goal; and (b) that it is essential to the experience of frustration that it fails to motivate us to pursue our goals. If both (a) and (b) were to be established, then the experience following the perception of an unexpected non-reward couldn't be an experience of frustration. I won't discuss this version of the argument here, for I don't find (a) and (b) very promising.

[3] I am grateful to Cecilea Mun for a very helpful discussion on this issue.

[4] Many thanks again to Cecilea Mun for suggesting to me this possible reading of Hardcastle's position.

[5] There is, of course, a debate as to whether boredom could be "objectless," insofar as it could lack a specific intentional object (target) (e.g., Feldges and Pieczenko 2020; Heidegger 1995). It is unclear, however, what the possibility of objectless boredom entails. Does it show that boredom can sometimes turn into a mood? Or does it suggest that there are at least two different kinds of boredom - an emotion-like state with a specific intentional object and a different state that lacks such an object? Or does it perhaps demonstrate that some emotional states can be "objectless"? Neither possibility raises serious trouble for my position. First, as I make clear in the body of the text, I treat the claim that boredom is an emotion as a serviceable hypothesis and not as an absolute claim about its nature. Second, even if boredom is sometimes objectless, then this realization is still consistent with my account and the overall position sketched out in Propelled. What is crucial for my thesis is that boredom serves a useful function in our lives. Importantly, the functional account of boredom doesn't require that boredom is an emotion.

[6] In the concluding section of her commentary, Pismenny offers a series of illuminating questions and comments on boredom's relationship to prudential action, morality, and aesthetics. I agree with much of what she says in that section and especially with her discussion on the aesthetic value of boredom. Yet I still hold that boredom has an important role to play in our life. I won't discuss what I take to be boredom's potential contributions to these domains of life here. If I were to do so, I would invariably end up repeating what I have said both in Propelled and in other works (read, e.g., Elpidorou 2017a, 2017b, 2018b, 2020; Elpidorou and Gibson in-press), and that would be boring, both for me but especially for the reader. 
[7] It is well known that boredom is intimately related not just to an inability to pay attention to one's situation but also to the perception that one's situation is meaningless. I won't adjudicate between attentional theories and other theories of boredom here. Still, I would like to point out that proponents of the attentional theory could argue that a perception of meaninglessness is a consequence of attentional difficulties. In other words, a situation strikes us as meaningless because we cannot pay attention to it. I am not convinced that this proposed causal relationship can account for all instances of perceived meaninglessness during boredom. Is it really impossible to be cognitively engaged with a situation while bored by it? Couldn't we, for instance, be bored while playing and thus engaging with a meaningless game on our phone? Indeed, recent empirical evidence offers support for the contention that attentional difficulties and perceived meaninglessness might be distinct elicitors (or causes) of boredom (read Westgate and Wilson 2018). If it turns out that attentional difficulties and perceived meaninglessness are sufficient but not necessary conditions for boredom, then either the attentional theory would need to be revised or we would need to conclude that there are different types of boredom. If the latter option is accepted, then we would have to hold that boredom may have distinct formal objects depending on what kind of boredom (attentional boredom or meaningless boredom) we are considering.

[8] I'm not the first person to argue for this conclusion. Bortolotti and Aliffi (forthcoming) have provided strong arguments in support of this conclusion.

[9] Moreover, a popular operationalization of trait boredom relates it to the frequent experience of ordinary boredom (Farmer and Sundberg 1986). Yet if we accept Heidegger's account, profound boredom doesn't depend on how frequently one experiences (ordinary) boredom. In fact, one might suggest that profound boredom is existentially significant precisely because it is a rare occurrence (Heidegger 1995, 135).

[10] There is another possibility here. The experiencing agent might, in the face of deep boredom, become energized. That is, one might seek to escape boredom, even if deep boredom is so comprehensive that escape from boredom isn't possible. Although such a scenario cannot be ruled out, it won't last. The agent would eventually resign and admit that no task will alleviate their boredom. Thus, the outcome of this scenario is ultimately the same as that discussed in the main text. Sooner or later, the motivational force of deep boredom will be reduced. 


\section{References}

Abler, B., H. Walter, and S. Erk. 2005. “Neural Correlates of Frustration.” Neuroreport 16, no. 7: 669-672.

Adams, F., and K. Aizawa. 2017. "Causal Theories of Mental Content." In The Stanford Encyclopedia of Philosophy, edited by E. N. Zalta. Summer Edition. https://plato.stanford.edu/archives/sum2017/entries/content-causal/.

Amsel, A. 1958. "The Role of Frustrative Nonreward in Noncontinuous Reward Situations." Psychological Bulletin 55, no. 2: 102-119. https://doi.org/10.1037/h0043125. 1992. Frustration Theory: An Analysis of Dispositional Learning and Memory. Cambridge, UK: Cambridge University Press.

Bargdill, R. W. 2000. “The Study of Life Boredom.” Journal of Phenomenological Psychology 3, no. 2: 188-219. https://doi.org/10.1163/15691620051090979.

Bench, S. W., Bera, J. L., and Cox, J. 2020. "State Boredom Results in Optimistic Perception of Risk and Increased Risk-Taking." Cognition and Emotion: 1-15. Advance online publication. https://doi.org/10.1080/02699931.2020.1858760.

Bench, S. W., and H. C. Lench. 2013. "On the Function of Boredom." Bebavioral Sciences 3, no. 3: 459-472. https://doi.org/10.3390/bs3030459.

Bench, S. W., and Lench, H. C. 2019. "Boredom as a Seeking State: Boredom Prompts the Pursuit of Novel (Even Negative) Experiences.” Emotion 19, no. 2: 242-254. https://doi.org/10.1037/emo0000433.

Berkowitz, L. 1988. "Frustrations, Appraisals, and Aversively Stimulated Aggression.” Aggressive Behavior 14, no. 1: 3-11. https://doi.org/10.1002/1098-2337(1988)14:1<3::AID-AB2480140103>3.0.CO;2-F, . 1989. "Frustration-aggression Hypothesis: Examination and Reformulation.” Psychological Bulletin 106, no. 1: 59-73. https://doi.org/10.1037/0033-2909.106.1.59.

Bierzynska, M., M. Bielecki, A. Marchewka, W. Debowska, A. Duszyk, W. Zajkowski, M. Falkiewicz, A. Nowicka, J. Strelau, and M. Kossut. 2016. "Effect of Frustration on Brain Activation Pattern in Subjects with Different Temperament.” Frontiers in Psychology 6: 1989. https://doi.org/10.3389/fpsyg.2015.01989.

Bortolotti, L., and N. Aliffi. Forthcoming. "The Epistemic Benefits of Irrational Boredom.” In The Moral Psychology of Boredom, edited by A. Elpidorou. London, UK/New York, NY: Rowman and Littlefield. 
Burgmer, P., Forstmann, M., and Stavrova, O. 2019. Ideas are Cheap: When and Why Adults Value Labor Over Ideas." Journal of Experimental Psychology: General 148, no. 5: 824-844. https://doi.org/10.1037/xge0000473.

Buss, A. H. 1961. The Psychology of Aggression. New York, NY: Wiley.

Çağlayan, E. 2016. "The Aesthetics of Boredom: Slow Cinema and the Virtues of the Long Take in Once Upon a Time in Anatolia.” Projections 10, no. 1: 63-85. https://doi.org/10.3167/proj.2016.100108.

Caldwell, L. L., N. Darling, L. L. Payne, and B. Dowdy. 1999. “'Why are You Bored?': An Examination of Psychological and Social Control Causes of Boredom Among Adolescents." Journal of Leisure Research 31, no. 2: 103-121. https://doi.org/10.1080/00222216.1999.11949853.

Csikszentmihalyi, M. 1975. Beyond Boredom and Anxiety. San Francisco, CA: Jossey-Bass.

Chan, C. S., W. A. van Tilburg, E. R. Igou, C. Y. Poon, K. Y. Tam, V. U. Wong, and S. K. Cheung. 2018. "Situational Meaninglessness and State Boredom: Cross-sectional and Experience Sampling Findings." Motivation and Emotion 42, no. 4: 555-565. https://doi.org/10.1007/s11031-018-9693-3.

Daschmann, E. C., T. Götz, and R. H. Stupnisky. 2011. "Testing the Predictors of Boredom at School: Development and Validation of the Precursors to Boredom Scales.” British Journal of Educational Psychology 81, no. 3: 421-440. https://doi.org/10.1348/000709910X526038.

Deonna, J. A., and F. Teroni. 2015. "Emotions as Attitudes." Dialectica 69, no. 3: 293-311. https://doi.org/10.1111/1746-8361.12116.

Deveney, C. M., M. E. Connolly, C. T. Haring, B. L. Bones, R. C. Reynolds, P. Kim, D. S. Pine, and E. Leibenluft. 2013. "Neural Mechanisms of Frustration in Chronically Irritable Children." American Journal of Psychiatry 170, no. 10: 1186-1194. https://doi.org/10.1176/appi.ajp.2013.12070917.

Dixon, M. J., V. MacLaren, M. Jarick, J. A. Fugelsang, and K. A. Harrigan. 2013. “The Frustrating Effects of Just Missing the Jackpot: Slot Machine Near-misses Trigger Large Skin Conductance Responses, But No Post-Reinforcement Pauses.” Journal of Gambling Studies 29, no. 4: 661-674. https://doi.org/10.1007/s10899-012-9333-x.

Dollard, J., Miller, N. E., Doob, L. W., Mowrer, O. H., and Sears, R. R. 1939. Frustration and Aggression. New Haven, CT: Yale University Press. https://doi.org/10.1037/10022-000.

Do-Monte, F. H., A. Minier-Toribio, K. Quiñones-Laracuente, E. M. Medina-Colón, and G. J. Quirk. 2017. “Thalamic Regulation of Sucrose Seeking During Unexpected Reward Omission.” Neuron 94, no. 2: 388-400.

Dretske, F. I. 1995. Naturalizing the Mind. Cambridge, MA: MIT Press. 
Eastwood, J. D., Frischen, A., Fenske, M. J., and Smilek, D. 2012. "The Unengaged Mind: Defining Boredom in Terms of Attention.” Perspectives on Psychological Science 75: 482-495. https://doi.org/10.1177/1745691612456044.

Elpidorou, A. 2014. “The Bright Side of Boredom.” Frontiers in Psychology 5: 1245. https://doi.org/10.3389/fpsyg.2014.01245. .2017a. “The Moral Dimensions of Boredom: A Call for Research.” Review of General Psychology 21, no. 1: 30-48. https://doi.org/10.1037/gpr0000098.

.2017b. "Boredom in Art." Behavioral and Brain Sciences 40: e359.

https://doi.org/10.1017/S0140525X17001674.

2018a. "The Good of Boredom.” Philosophical Psychology 31, no. 3: 323-351.

https://doi.org/10.1080/09515089.2017.1346240.

. 2018b. "The Bored Mind Is a Guiding Mind: Toward a Regulatory Theory of Boredom.”

Phenomenology and the Cognitive Sciences 17, no. 3: 455-484.

https://doi.org/10.1007/s11097-017-9515-1.

.2018c. "On Affect: Function and Phenomenology." Humana.Mente Journal of Philosophical Studies, 11, no. 34: 155-184.

. and L. Freeman. 2019. “Is Profound Boredom Boredom?” In Heidegger on Affect, edited by C. Hadjioannou, 177-203. Cham, Switzerland: Palgrave Macmillan.

.2020. Propelled: How Boredom, Frustration, and Anticipation Lead Us to the Good Life. New York, NY: Oxford University Press.

. 2022. "The Moral Significance of Boredom: An Introduction.” In Moral Psychology of Boredom, edited by A. Elpidorou, 1-33. Lanham, MD: Rowman \& Littlefield.

Elpidorou A., and J. Gibson (in press). "Really Boring Art.” Ergo.

Fahlman, S. A., K. B. Mercer-Lynn, D. B. Flora, and J. D. Eastwood. 2013. "Development and Validation of the Multidimensional State Boredom Scale.” Assessment 20: 68-85. https://doi.org/10.1177/1073191111421303.

Farmer, R., and N. D. Sundberg. 1986. "Boredom Proneness-the Development and Correlates of a New Scale.” Journal of Personality Assessment 50, no. 1: 4-17. https://doi.org/10.1207/s15327752jpa5001_2.

Feldges, T., and S. Pieczenko. 2020. "Boredom in Educational Contexts: A Critical Review.” Encyclopaideia 24, no. 57: 1-15. https://doi.org/10.6092/issn.1825-8670/11035 
Fisher, C. D. 1993. "Boredom at Work: A Neglected Concept.” Human Relations 46: 395-417. https://doi.org/10.1177/001872679304600305.

Fodor, J. 1990. A Theory of Content and Other Essays. Cambridge, MA: MIT/Bradford Press. 1994. The Elm and the Expert. Cambridge, MA: MIT/Bradford.

Goldberg, Y. K., J. D. Eastwood, J. LaGuardia, and J. Danckert. 2011. “Boredom: An Emotional Experience Distinct from Apathy, Anhedonia, or Depression.” Journal of Social and Clinical Psychology 30, no. 6: 647-666. https://doi.org/10.1521/jscp.2011.30.6.647.

Havermans, R. C., Vancleef, L., Kalamatianos, A., and Nederkoorn, C. 2015. "Eating and Inflicting Pain Out of Boredom.” Appetite 85: 52-57. https://doi.org/10.1016/j.appet.2014.11.007.

Heidegger, M. 1995. Basic Concepts of Metaphysics: World-Finitude-Solitude. Translated by W. McNeil and N. Walker. Bloomington, IN: Indiana University Press. Originally publication: 1929-30/1983. Die Grundbegriffe der Metaphysik. Welt, Endlichkeit, Einsamkeit. GA 29/30. Frankfurt am Main: Vittorio Klostermann.

Inzlicht, M., A. Shenhav, and C. Y. Olivola. 2018. "The Effort Paradox: Effort is Both Costly and Valued.” Trends in Cognitive Sciences 22, no. 4: 337-349. https://doi.org/10.1016/j.tics.2018.01.007.

Jeronimus, B. F., and O. M. Laceulle. 2017. “Frustration.” In Encyclopedia of Personality and Individual Differences, edited by V. Zeigler-Hill and T. K. Shackelford, 1- 8. New York, NY: Springer. https://doi.org/10.1007/978-3-319-28099-8_815-1.

Kanngiesser, P., and Hood, B. 2014. "Not by labor alone: Considerations for Value Influence Use of the Labor Rule in Ownership Transfers.” Cognitive Science 38, no. 2: 353-366. https://doi.org/10.1111/cogs.12095.

Kruglanski, A. W., M. Chernikova, and K. Jasko. 2018. “The Forward Rush: On Locomotors' Future Focus.” In The Psychology Of Thinking About The Future, edited by G. Oettingen, A. T. Sevincer, and P. M. Gollwitzer, 405-422. New York, NY: Guilford Press.

Kruglanski, A. W., A. Pierro, L. Mannetti, and T. E. Higgins. 2013. “The Distinct Psychologies of 'Looking' and 'Leaping': Assessment and Locomotion as the Springs of Action." Social and Personality Psychology Compass 7, no. 2: 79-92. https://doi.org/10.1111/spc3.12015.

Kupperman, J. J. 2006. Six Myths About the Good Life: Thinking About What Has Value. Indianapolis, IN: Hackett Publishing.

Kurzban, R. 2016. “The Sense of Effort.” Current Opinion in Psychology 7: 67-70. https://doi.org/10.1016/j.copsyc.2015.08.003. 
Kurzban, R. A. Duckworth, J. W. Kable, and J. Myers. 2013. "An Opportunity Cost Model of Subjective Effort and Task Performance.” Behavioral and Brain Sciences 36, no. 6: 661-679. https://doi.org/10.1017/S0140525X12003196.

Larsen, J. T., N. A. Coles, and D. K. Jordan. 2017. "Varieties of Mixed Emotional Experience.” Current Opinion in Behavioral Sciences 15: 72-76. https://doi.org/10.1016/j.cobeha.2017.05.021.

Maltsberger, J. T. 2000. "Mansur Zaskar: A Man Almost Bored To Death.” Suicide and Life-Threatening Behavior 30, no. 1: 83-90.

Martin, M., G. Sadlo, and G. Stew. 2006. “The Phenomenon of Boredom.” Qualitative Research in Psychology 3, no. 3: 193-211. https://doi.org/10.1191/1478088706qrp066oa.

Mendelovici, A., and D. Bourget. 2014. "Naturalizing Intentionality: Tracking Theories Versus Phenomenal Intentionality Theories.” Philosophy Compass 9, no. 5: 325-337. https://doi.org/10.1111/phc3.12123.

Matravers, D. 1995. Is boring art just boring? Journal of Aesthetics and Art Criticism 53, no. 4: 425-426. https://doi.org/10.1111/1540_6245.jaac53.4.0425.

Menninghaus, W., Wagner, V., Hanich, J., Wassiliwizky, E., Jacobsen, T., and Koelsch, S. 2017. "The Distancing-Embracing Model of the Enjoyment of Negative Emotions in Art Reception.” Behavioral and Brain Sciences 40: E347. https://doi.org/10.1017/S0140525X17000309.

Millikan, R. 1989. “Biosemantics.” Journal of Philosophy 86: 281-97. https://doi.org/10.2307/2027123 2004. Varieties of Meaning. Cambridge, MA: MIT Press.

Mochon, D., Norton, M. I., and Ariely, D. 2012. "Bolstering and Restoring Feelings of Competence via the IKEA Effect." International Journal of Research in Marketing 29, no. 4: 363-369. https://doi.org/10.1016/j.ijresmar.2012.05.001.

Moller, D. 2014. "The Boring." The Journal of Aesthetics and Art Criticism 72, no. 2: 181-191. https://doi.org/10.1111/jaac.12074.

Moynihan, A. B., E. R. Igou, and W. A. van Tilburg. 2020. "Existential Escape of the Bored: A Review of Meaning-Regulation Processes Under Boredom.” European Review of Social Psychology. Early Access. https://doi.org/10.1080/10463283.2020.1829347.

Myrtek, M., D. Zanda, and E. Aschenbrenner. 2001. "Interactive Psychophysiological Monitoring of Emotions in Students' Everyday Life. A Replication Study.” In Progress in Ambulatory Assessment: Computer-Assisted Psychological and Psychophysiological Methods in Monitoring and Field Studies, edited by J. Fahrenberg and M. Myrtek, 415-434. Kirkland, WA: Hogrefe and Huber. 
Neander, K. 2017. A Mark of the Mental: In Defense of Informational Teleosemantics. Cambridge, MA: MIT Press.

Neander, K., and P. Schulte. Forthcoming. "Teleological Theories of Mental Content.” In The Stanford Encyclopedia of Philosophy, edited by E. N. Zalta. Spring 2021 Edition. https://plato.stanford.edu/archives/spr2021/entries/content-teleological.

Nederkoorn, C., Vancleef, L., Wilkenhöner, A., Claes, L., and Havermans, R. C. 2016. "Self-Inflicted Pain Out of Boredom.” Psychiatry Research 237: 127-132. https://doi.org/10.1016/j.psychres.2016.01.063.

Neu, J. 1998. "Boring from Within: Endogenous Versus Reactive Boredom.” In Emotions In Psychopathology: Theory and Research, edited by W. F. Flack and J. D. Laird, 158-170. London, England: Oxford University Press.

Nisbet, R. 1982. Boredom. In Prejudices: A Philosophical Dictionary. Cambridge, MA: Harvard University Press.

Norton, M. I., Mochon, D., and Ariely, D. 2012. “The IKEA Effect: When Labor Leads to Love.” Journal of Consumer Psychology 22, no. 3: 453-460. https://doi.org/10.1016/j.jcps.2011.08.002.

Otis, J., and R. Ley. 1993. "The Effects of Frustration Induced by Discontinuation of Reinforcement on Force of Response and Magnitude of the Skin Conductance Response." Bulletin of the Psychonomic Society 31, no. 2: 97-100. https://doi.org/10.3758/BF03334150.

Papineau, D. 1987. Reality and Representation. Oxford, England: Basil Blackwell. . 1998. “Teleosemantics and Indeterminacy.” Australasian Journal of Philosophy 76, no. 1: 1-14. https://doi.org/10.1080/00048409812348151.

Papini, M. R. 2003. “Comparative Psychology of Surprising Nonreward.” Brain, Behavior and Evolution 62, no. 2: 83-95. https://doi.org/10.1159/000072439.

Papini, M. R., and R. T. Dudley. 1997. "Consequences of Surprising Reward Omissions.” Review of General Psychology 1, no. 2: 175-197. https://doi.org/10.1037/1089-2680.1.2.175.

Pekrun, R., T. Goetz, L. M. Daniels, R. H. Stupnisky, and R. P. Perry. 2010. "Boredom in Achievement Settings: Exploring Control-value Antecedents and Performance Outcomes of a Neglected Emotion.” Journal of Educational Psychology 102: 531-549.

Pfattheicher, S., Lazarević, L. B., Westgate, E. C., and Schindler, S. 2020. "On the Relation of Boredom and Sadistic Aggression. Journal of Personality and Social Psychology. Advance online publication. https://doi.org/10.1037/pspi0000335. 
Prinz, J. J. 2004. Gut Reactions: A Perceptual Theory of Emotion. Oxford, England: Oxford University Press.

Rozin, P. 1999. "Preadaptation and the Puzzles and Properties of Pleasure.” In Well-Being: The Foundations of Hedonic Psychology, edited by D. Kahnema, E. Diener, and N. Schwarz, 109-133. New York, NY: Sage.

Sarstedt, M., Neubert, D., and Barth, K. 2017. “The IKEA Effect. A Conceptual Replication.” Journal of Marketing Behavior 2, no. 4: 307-312. http://dx.doi.org/10.1561/107.00000039.

Scherer, K. R. 2005. "What are Emotions? And How Can They Be Measured?" Social Science Information 44, no. 4: 695-729. https://doi.org/10.1177/0539018405058216.

Steinberger, F., A. Moeller, and R. Schroeter. 2016. "The Antecedents, Experience, and Coping Strategies of Driver Boredom in Young Adult Males.” Journal of Safety Research 59: 69-82. https://doi.org/10.1016/j.jsr.2016.10.007.

Strohl, M. 2019. “Art and Painful Emotion.” Philosophy Compass 14, no. 1: e12558. https://doi.org/10.1111/phc3.12558.

Trampe, D., J. Quoidbach, and M. Taquet. 2015. "Emotions in Everyday Life.” PLOS ONE 10, no. 12: e0145450. https://doi.org/10.1371/journal.pone.0145450

van Aart, J., Bartneck, C., Hu, J., Rauterberg, M., and Salem, B. 2010. "How to Behave as Alice in Wonderland-About Boredom and Curiosity.” Entertainment Computing 1, no. 3-4: 125-137. https://doi.org/10.1016/j.entcom.2010.09.003.

van Hooft, E. A., and M. L. van Hooff. 2018. "The State of Boredom: Frustrating or Depressing?” Motivation and Emotion 41, no.6: 931-946. https://doi.org/10.1007/s11031-018-9710-6.

Van Tilburg, W. A., and E. R. Igou. 2011. "On Boredom and Social Identity: A Pragmatic Meaning-Regulation Approach.” Personality and Social Psychology Bulletin 37: 1679-1691. https://doi.org/10.1177/0146167211418530.

2012. "On Boredom: Lack of Challenge and Meaning as Distinct Boredom Experiences." Motivation and Emotion 36, no. 2: 181-194. https://doi.org/10.1007/s11031-011-9234-9.

. 2017. “Boredom Begs to Differ: Differentiation From Other Negative Emotions.” Emotion 17, no. 2: 309-322. https://doi.org/10.1037/emo0000233.

Vodanovich, S. J. 2003. "Psychometric Measures of Boredom: A Review of the Literature." The Journal of Psychology 137, no. 6: 569-595. https://doi.org/10.1080/00223980309600636. 
Vodanovich, S. J., and J. D. Watt. 2016. "Self-Report Measures of Boredom: An Updated Review of the Literature.” The Journal of Psychology 150, no. 2: 196-228. https://doi.org/10.1080/00223980.2015.1074531.

Westgate, E. C., and T. D. Wilson. 2018. "Boring Thoughts and Bored Minds: The Mac Model of Boredom and Cognitive Engagement.” Psychological Review 125, no. 5: 689-713. https://doi.org/10.1037/rev0000097.

Wilson, T. D., Reinhard, D. A., Westgate, E. C., Gilbert, D. T., Ellerbeck, N., Hahn, C., Brown, C. L., and Shaked, A. 2014. "Just Think: The Challenges of the Disengaged Mind.” Science 345, no. 6192: 75-77. https://doi.org/10.1126/science.1250830.

Wilhelm, P., D. Schoebi, and M. Perrez. 2004. "Frequency Estimates of Emotions in Everyday Life From a Diary Method's Perspective: A Comment On Scherer Et Al.'s Survey-Study 'Emotions in Everyday Life.'” Social Science Information 43, no. 4: 647-65. https://doi.org/10.1177/0539018404047712.

Yu, R. 2016. “The Neural Basis of Frustration State.” In Neuroimaging Personality, Social Cognition, and Character, edited by J. R. Absher and J. Cloutier, 223-243. London, UK: Academic Press. https://doi.org/10.1016/B978-0-12-800935-2.12001-9.

Yu, R., D. Mobbs, B. Seymour, J. B. Rowe, and A. J. Calder. 2014. "The Neural Signature of Escalating Frustration in Humans." Cortex 54: 165-178. https://doi.org/10.1016/j.cortex.2014.02.013. 